\title{
Effect of smoking habits on sleep
}

\author{
S.G. Conway ${ }^{1,2}$, S.S. Roizenblatt ${ }^{1,2}$, L. Palombini ${ }^{1}$, L.S. Castro ${ }^{2}$, L.R.A. Bittencourt ${ }^{1,2}$, \\ R.S. Silva ${ }^{2}$ and S. Tufik ${ }^{1,2}$ \\ ${ }^{1}$ Instituto do Sono - Associação Fundo de Incentivo à Psicofarmacologia, São Paulo, SP, Brasil \\ ${ }^{2}$ Departamento de Psicobiologia, Escola Paulista de Medicina, Universidade Federal de São Paulo, \\ São Paulo, SP, Brasil
}

Correspondence to: S.G. Conway, R. Dr. Napoleão de Barros, 925, 04024-002 São Paulo, SP, Brasil Fax: +55-11-5908-7700. E-mail: silvia@psicobio.epm.br

To evaluate the effect of smoking habits on sleep, data from 1492 adults referred to the Sleep Institute were accessed and divided into 3 categories of smoking status: current, former and non-smokers. Categories of pack-years ( $<15$ and $\geq 15)$ defined smoking severity. The association of smoking status and smoking severity with sleep was analyzed for sleep parameters, especially apnea and hypopnea index $(\mathrm{AHI}) \geq 5$, more than $5 \%$ of total sleep time $(\mathrm{TST})$ spent with oxyhemoglobin saturation $\left(\mathrm{SaO}_{2}\right)<90 \%$, and arousal index. The arousal index was higher among current $(21 \pm 17)$ and former smokers $(20 \pm 17)$ than non-smokers (17 $\pm 15 ; \mathrm{P}<0.04)$. Former smokers had a higher percent of $\mathrm{TST}_{\text {at }} \mathrm{SaO}_{2}<90 \%$ than non-smokers $(9 \pm 18$ vs $6 \pm 13 ; \mathrm{P}<0.04)$. Former smokers with pack-years $\geq 15$ compared to $<15$ exhibited higher $\mathrm{AHI}(22 \pm 24$ vs $16 \pm 21 ; \mathrm{P}<0.05)$ and arousal index (22 \pm 19 vs $18 \pm 15 ; P<0.05)$. Current smokers with pack-years $\geq 15$ compared to <15 exhibited higher arousal index ( $23 \pm 18$ vs $18 \pm 16$; $P<0.05)$ and percent of TST at $\mathrm{SaO}_{2}<90 \%(11 \pm 17$ vs $6 \pm 13 ; \mathrm{P}<0.05)$. Smoking status and pack-years were not associated with $\mathrm{AHI} \geq 5$ on logistic regression analysis, but current smokers with pack-years $\geq 15$ were 1.9 times more likely to spend more than $5 \%$ of $\mathrm{TST}$ at $\mathrm{SaO}_{2}<90 \%$ than non-smokers $(95 \% \mathrm{Cl}=1.21-2.97 ; \mathrm{P}=0.005)$. The variability of arousal index was influenced by gender, $\mathrm{AHI}$ and current smokers with pack-years $\geq 15$ (all $\mathrm{P}<0.01$ ). Smoking habits seem to be associated with arousal and oxyhemoglobin desaturation during sleep, but not with $\mathrm{AHI}$. The effect was more pronounced in current than former smokers.

Key words: Smoking; Tobacco; Smoking cessation; Sleep; Sleep-disordered breathing

Presented at the XI Congresso Brasileiro do Sono. Fortaleza, CE, Brazil, November 11-14, 2007.

Research supported by Associação Fundo de Incentivo à Psicofarmacologia and FAPESP (\#98/14303-3).

Received November 5, 2007. Accepted July 31, 2008

\section{Introduction}

Adverse health effects due to cigarette smoking have been exhaustively documented. The most researched consequences of smoking are respiratory cancer and chronic obstructive pulmonary disease (1-4). Despite copious literature on the subject, the effects of smoking upon sleep have not been completely established. Most studies in this field are based on questionnaires (5-16) and show that smokers subjectively report difficulty falling asleep and maintaining sleep (5-7). These disturbances are attributed to the stimulating effect of nicotine $(7,8)$ and increased occurrence of snoring (9-13), even among passive smokers (14-16). The use of objective sleep parameters is restricted to only a few published studies (17-21).

Wetter et al. (21), in a sleep cohort study, found that current smokers were more closely associated with snoring and moderate or severe sleep-disordered breathing than non-smokers. Kashyap et al. (17), in a controlled study, found that the prevalence of current smokers among patients with an apnea-hypopnea index $(\mathrm{AHI})$ greater than 10 was higher compared with normal controls. Hoffstein (18) demonstrated that, although smoking status and amount of pack-years smoked was not associated with an increased $\mathrm{AHI}$ (18), there was a greater number of current smokers and average pack-years among individuals with $\mathrm{AHI} \geq 50$ than among those with $\mathrm{AHI}<10$ (18). Finally, Casasola et al. (19) reported that the nocturnal hypoxia 
index was higher in current smokers than in non-smokers, and that the pack-years smoked index correlated significantly with carboxyhemoglobin concentration as well as the nocturnal hypoxia index (19). These studies notwithstanding, the literature (5-21) only partially responds to the question of whether and how smoking habits and sleep are related. Moreover, only a few studies considered the former smoking condition $(17,18,20,21)$ or the number of packyears smoked (17-19). The purpose of the present study was to evaluate the effect of smoking status (current, former and non-smoker) and pack-years on objective sleep parameters, especially on respiratory parameters.

\section{Patients and Methods}

The study was conducted at the Department of Psychobiology at the Universidade Federal de São Paulo (UNIFESP). Data were collected for 3718 database patients referred to the Sleep Institute during the period of September 2004 through February 2005. The inclusion criteria for this data were: adult patients (30 to 70 years of age), not under treatment for obstructive sleep apneahypopnea syndrome (i.e., not in use of positive airway pressure equipment (CPAP/BIPAP) or oral appliances and those who had not been submitted to surgery to treat apnea) and with baseline oxyhemoglobin saturation $\left(\mathrm{SaO}_{2}\right)$ over $90 \%$ (in order to prevent inclusion of patients with primary lung disease). Data for 1492 cases were included in the present investigation.

\section{Database}

Anthropometric data included age, gender and body mass index (BMI). Smoking status (current, former and non-smoker) was determined by three possible answers to the question: "Are you a smoker?" ("yes", "I was", "no"). Moreover, smoking at least 100 cigarettes during life, and with no discontinuation, was used as the criterion for current smokers $(22,23)$. The amount someone had or has smoked, referred as pack-years, was calculated multiplying years smoking by number of packs per day. Periods of smoking cessation were not included in this calculation. Pack-years were grouped into two categories according to severity ( $<15$ and $\geq 15$ ), according to the cut-off point of the median of the pack-years variable. Daytime sleepiness was evaluated by the Epworth Sleepiness Scale (24) and a score of 10 was utilized as the normality threshold (24).

Nocturnal polysomnograph (PSG) data included in this study were sleep latency, sleep efficiency, percent of sleep stages, arousal index, $\mathrm{AHI}$, baseline $\mathrm{SaO}_{2}$ and percentage of TST at $\mathrm{SaO}_{2}<90 \%$. PSG recordings were obtained using surface electrodes to continuously record 4-chan- nels of electroencephalography (EEG; C3-A2, C4-A1, O1A2, O2-A1), electrooculogram (LOG-A2 and ROG-A1), submental and tibialis electromyography, electrocardiography, nasal airflow, thoracic and abdominal respiratory effort, finger oxymetry, and snore microphone. PSG was scored manually according to the criteria of Rechtschaffen and Kales (25) by an experienced sleep technician and reviewed by a sleep medicine physician. EEG arousals lasting more than $3 \mathrm{~s}$ were scored manually according to the American Sleep Disorders Association (ASDA) Task Force criteria (26). Apnea and hypopnea are defined according to the American Academy of Sleep Medicine (AASM) Task Force report (27). Apnea is defined as a cessation for at least $10 \mathrm{~s}$ (>90\% from previous amplitude) of inspiratory airflow. Obstructive apnea is characterized as the absence of airflow with continued respiratory effort. Central apnea is defined as the absence of airflow and respiratory effort. Hypopnea is an airflow reduction (>50\% from previous amplitude) lasting $10 \mathrm{~s}$ or more and associated with $\mathrm{SaO}_{2}$ dropping at least $3 \%$ and EEG arousal. The $\mathrm{AHI}$ is defined as the number of apneas and hypopneas per hour of sleep, and $\mathrm{AHI} \geq 5$ was considered to be abnormal. The desaturation index is a decrease greater than $3 \%$ of the number of arterial oxygen desaturations per total sleep time (TST). The percent of TST spent with $\mathrm{SaO}_{2}$ below $90 \%$ was also measured, and considered abnormal when above $5 \%$.

This study was based on information in a retrospective database, constructed at the Sleep Institute, which has a capacity of approximately 80 sleep laboratory beds. The records were obtained by internationally recognized instruments [Oxford (England), Sonolab (Brazil), Embla (USA), Polysmith (USA), Stellate (Canada), and Alice 4 (USA)].

\section{Data analysis}

All statistical analyses were performed using the SPSS 13.0 statistical software $(28)$ and $P<0.05$ was the significance level adopted. Normality was tested by the ShapiroWilk test. Data normally distributed were evaluated by the Student $t$-test or ANOVA followed by the Tukey Honest significant difference test. For non-normal distributed data, differences were analyzed by the Mann-Whitney U-test or Kruskal-Wallis ANOVA followed by the multiple comparison test. Categorical data were analyzed by the chi-square test.

Binary logistic regression was performed to identify possible associations of smoking related variables (status and pack-years) to $\mathrm{AHI} \geq 5$ and percent of TST above 5 at $\mathrm{SaO}_{2}<90 \%$. BMI, gender, and age were controlled in both analyses, while $\mathrm{AHI}$ only for the second. The non-smokers group was adopted as reference group. Linear regression analyses were conducted in an all sample-based model to 
determine whether gender, age, $\mathrm{BMI}, \mathrm{AHI}$, smoking status, and severity could influence arousal index. The same procedure was performed for the Epworth Sleepiness Scale. For each significant predictor, the unstandardized coefficient (B), standard error, and $\mathrm{P}$ value were reported.

\section{Results}

Tables 1 and 2 summarize the anthropometric and PSG characteristics according to the smoking status and categories of packyears, respectively. The former smokers group was on average the oldest and had higher BMI and Epworth Sleepiness Scale scores compared with non-smokers. Nonsmokers presented the lowest arousal index. Current smokers showed increased $\mathrm{N}$ REM sleep stage 1 and decreased slowwave sleep compared with non-smokers, while former smokers had an increased percent of TST at $\mathrm{SaO}_{2}<90 \%$.

The comparisons of categories of packyears (pack-years $\geq 15$ vs pack-years <15) for former smokers showed that the subgroup of pack-years $\geq 15$ was older, had higher BMI, Epworth Sleepiness Scale score, $\mathrm{AHI}$ and arousal index than the subgroup of pack-years <15 (Table 2). The comparisons of categories of pack-years for current smokers showed that the subgroup of pack-years $\geq 15$ was older, had a greater proportion of men, higher arousal index and percent of (ANOVA).
TST at $\mathrm{SaO}_{2}<90 \%$ than the subgroup of pack-years $<15$ (Table 2).

In a model controlled for BMI, gender and age, the logistic regression analyses showed that neither smoking status (current and former smokers) nor pack-years were associated with $\mathrm{AHI} \geq 5$ compared to non-smokers. Also when controlled for $\mathrm{BMI}$, gender, age and $\mathrm{AHI}$, the analysis

Table 1. Characteristics of patients according to smoking status.

\begin{tabular}{|c|c|c|c|}
\hline & Non-smoker & Current smoker & Former smoker \\
\hline Number & 948 (63.5\%) & 254 (17.0\%) & 290 (19.4\%) \\
\hline Age (years) & $45.6 \pm 10.5$ & $45.0 \pm 8.8$ & $48.4 \pm 9.3^{* *}$ \\
\hline BMI $\left(\mathrm{kg} / \mathrm{m}^{2}\right)$ & $27.9 \pm 4.9$ & $27.8 \pm 4.8$ & $29.0 \pm 5.4^{*}$ \\
\hline Gender (female:male) & $1: 1.7$ & $1: 2.2^{+}$ & $1: 2.3^{+}$ \\
\hline Pack-years & 0 & $22.9 \pm 19.7$ & $22.5 \pm 24.5$ \\
\hline Epworth Sleepiness Scale & $9.4 \pm 5.4$ & $9.9 \pm 5.3$ & $10.3 \pm 5.0^{*}$ \\
\hline $\mathrm{AHI}$ & $15.8 \pm 20.1$ & $17.6 \pm 21.5$ & $19.0 \pm 22.3$ \\
\hline $\mathrm{AHI} \geq 5$ & $589(62.1 \%)$ & $167(65.7 \%)$ & $196(67.6 \%)$ \\
\hline$\%$ TST at $\mathrm{SaO}_{2}<90 \%$ & $6.2 \pm 13.5$ & $8.3 \pm 15.6$ & $9.1 \pm 18.0^{*}$ \\
\hline Arousal index & $17.0 \pm 15.0^{* *}$ & $20.7 \pm 17.1$ & $20.1 \pm 17.0$ \\
\hline Sleep latency (min) & $17.2 \pm 22.7$ & $17.8 \pm 17.6$ & $19.6 \pm 20.6$ \\
\hline Sleep efficiency (\%) & $82.8 \pm 10.5$ & $82.6 \pm 10.1$ & $81.1 \pm 11.5$ \\
\hline Sleep stage $1(\%)$ & $4.1 \pm 2.9$ & $4.7 \pm 3.6^{*}$ & $4.5 \pm 3.3$ \\
\hline Sleep stage $2(\%)$ & $58.0 \pm 11.7$ & $60.0 \pm 11.7$ & $58.4 \pm 13.0$ \\
\hline Slow wave sleep (\%) & $19.0 \pm 10.0$ & $17.0 \pm 10.4^{+}$ & $18.6 \pm 11.3$ \\
\hline REM sleep (\%) & $18.9 \pm 6.9$ & $18.4 \pm 7.0$ & $18.5 \pm 7.8$ \\
\hline
\end{tabular}

Data are reported as mean \pm SD or as number and percent. BMI $=$ body mass index $\left(\mathrm{kg} / \mathrm{m}^{2}\right) ; \mathrm{AHI}=$ apnea and hypopnea index defined as the number of apneas and hypopneas per hour of sleep; \% TST at $\mathrm{SaO}_{2}<90 \%=$ percent of total sleep time at saturation of oxyhemoglobin less than $90 \%$.

${ }^{*} \mathrm{P}<0.04$ compared to non-smokers (Kruskal-Wallis test); ${ }^{* *} \mathrm{P}<0.05$ compared to other groups (Kruskal-Wallis test); ${ }^{+} \mathrm{P}<0.04$ compared to non-smokers

Table 2. Characteristics of current and former smokers according to pack-year classification.

\begin{tabular}{|c|c|c|c|c|}
\hline & \multicolumn{2}{|c|}{ Current smokers } & \multicolumn{2}{|c|}{ Former smokers } \\
\hline & $\begin{array}{c}<15 \text { pack-years } \\
(N=117)\end{array}$ & $\begin{array}{l}\geq 15 \text { pack-years } \\
\quad(N=137)\end{array}$ & $\begin{array}{c}<15 \text { pack-years } \\
(N=147)\end{array}$ & $\begin{array}{c}\geq 15 \text { pack-years } \\
\quad(N=143)\end{array}$ \\
\hline Age (years) & $41.3 \pm 8.1$ & $48.2 \pm 8.2^{\star \star}$ & $45.5 \pm 8.9$ & $51.5 \pm 8.6^{\star \star}$ \\
\hline BMI $\left(\mathrm{kg} / \mathrm{m}^{2}\right)$ & $27.3 \pm 4.7$ & $28.3 \pm 4.9$ & $28.4 \pm 5.9$ & $29.6 \pm 4.7^{*}$ \\
\hline Gender (female:male) & $1: 1.6$ & $1: 2.9^{+}$ & $1: 1.9$ & $1: 2.8$ \\
\hline Epworth Seepiness Scale & $9.3 \pm 5.4$ & $10.5 \pm 5.1$ & $9.6 \pm 4.7$ & $11.0 \pm 5.3^{\star *}$ \\
\hline $\mathrm{AHI}$ & $16.3 \pm 22.0$ & $18.6 \pm 21.2$ & $16.0 \pm 20.6$ & $22.1 \pm 23.6^{*}$ \\
\hline$\%$ TST at $\mathrm{SaO}_{2}<90 \%$ & $5.6 \pm 13.2$ & $10.6 \pm 17.1^{*}$ & $6.4 \pm 14.5$ & $11.8 \pm 20.7$ \\
\hline Arousal index (per hour of sleep) & $18.2 \pm 15.9$ & $22.8 \pm 17.9^{*}$ & $18.0 \pm 14.9$ & $22.2 \pm 18.9^{*}$ \\
\hline
\end{tabular}

Data are reported as mean $\pm \mathrm{SD}$ or as number. $\mathrm{BMI}=$ body mass index $\left(\mathrm{kg} / \mathrm{m}^{2}\right) ; \mathrm{AHI}=$ apnea and hypopnea index defined as the number of apneas and hypopneas per hour of sleep; \%TST at $\mathrm{SaO}_{2}<90 \%=$ percent of total sleep time at saturation of oxyhemoglobin less than $90 \%$.

Statistically significant differences within smoking groups: ${ }^{*} \mathrm{P}<0.05$ (Mann-Whitney U-test); ${ }^{*} \mathrm{P}<0.05$ (Student $t$-test); ${ }^{+} \mathrm{P}<0.05$ (chisquare test). 
considering the $\mathrm{SaO}_{2}<90 \%$ demonstrated that its permanency in more than 5\% TST is associated with current smokers with pack-years $>15(\mathrm{OR}=1.9,95 \% \mathrm{Cl}=1.21$ to 2.97; $\mathrm{P}=0.005$; Table 3). When gender, BMI, age, $\mathrm{AHI}$,

Table 3. Odds ratio, confidence intervals and $P$ values from logistic regression model for more than $5 \%$ of total sleep time at saturation of oxyhemoglobin less than $90 \%$.

\begin{tabular}{llll}
\hline & & OR & $95 \% \mathrm{Cl}$ \\
\hline Current smokers & Pack-years $<15$ & 0.83 & $(0.46 ; 1.50)$ \\
& Pack-years $\geq 15$ & $1.90^{*}$ & $(1.21 ; 2.97)$ \\
Former smokers & Pack-years $<15$ & 0.97 & $(0.59 ; 1.59)$ \\
& Pack-years $\geq 15$ & 1.39 & $(0.89 ; 2.18)$
\end{tabular}

Odds ratio (OR) was adjusted for body mass index, gender, age, smoking status and apnea-hypopnea index with the non-smokers as the reference group. Log-likelihood ratio: $P<0.001$. ${ }^{*} P=0.005$ compared to non-smokers (binary logistic regression).

Table 4. Parameter estimates and $P$ values for the regression model with arousal index as the dependent variable.

\begin{tabular}{lccr}
\hline Variable & B Coefficient & Standard error & P \\
\hline Constant & 7.19 & 1.76 & $<0.001$ \\
Gender & $1.43^{*}$ & 0.52 & 0.007 \\
Age & -0.03 & 0.02 & 0.275 \\
Body mass index & 0.02 & 0.05 & 0.637 \\
AHI & $0.63^{*}$ & 0.01 & $<0.001$ \\
Current smokers with pack-years $<15$ & 0.79 & 0.90 & 0.384 \\
Current smokers with pack-years $\geq 15$ & $4.25^{*}$ & 0.85 & $<0.001$ \\
Former smokers with pack-years $<15$ & 0.86 & 0.81 & 0.290 \\
Former smokers with pack-years $\geq 15$ & 1.56 & 0.84 & 0.064 \\
\hline
\end{tabular}

$\mathrm{AHI}=$ apnea and hypopnea index defined as the number of apneas and hypopneas per hour of sleep.

${ }^{*} \mathrm{P}<0.01$ (linear regression analyses).

Table 5. Parameter estimates and $P$ values for the regression model with Epworth Sleepiness Scale score as the dependent variable.

\begin{tabular}{lccr}
\hline Variable & B Coefficient & Standard error & $\mathrm{P}$ \\
\hline Constant & 8.23 & 1.02 & $<0.001$ \\
Gender & -0.41 & 0.30 & 0.172 \\
Age & -0.03 & 0.01 & 0.055 \\
Body mass index & $0.08^{* *}$ & 0.03 & 0.006 \\
AHI & $0.03^{* *}$ & 0.01 & 0.001 \\
Current smokers with pack-years $<15$ & -0.21 & 0.52 & 0.693 \\
Current smokers with pack-years $\geq 15$ & $0.96^{*}$ & 0.48 & 0.049 \\
Former smokers with pack-years $<15$ & 0.17 & 0.47 & 0.715 \\
Former smokers with pack-years $\geq 15$ & $1.40^{* *}$ & 0.49 & 0.004 \\
\hline
\end{tabular}

$\mathrm{AHI}=$ apnea and hypopnea index defined as the number of apneas and hypopneas per hour of sleep.

${ }^{*} \mathrm{P}<0.05 ;{ }^{* *} \mathrm{P}<0.01$ (linear regression analyses). smoking status and pack-year categories were considered, inear regression analysis demonstrated that gender, $\mathrm{AHI}$ and current smokers with pack-years $>15$ influenced the same variables for the Epworth Sleepiness Scale, the model revealed an influence of BMI, $\mathrm{AHI}$, current smokers with pack-years $\geq 15$, and former smokers with pack-years $\geq 15$ (Table 5).

\section{Discussion}

The present study demonstrates the association of sleepiness, sleep fragmentation, and oxyhemoglobin desaturation during sleep with the amount of pack-years smoked in a clinical population. The effect was more pronounced in current smokers than in former smokers.

Methodological differences among studies may explain or increase understanding of the controversy of the effect of tobacco smoking on sleep $(5-19,21)$. The first publications were based on questionnaires without objective measures of smoking habits or sleep parameters $(5-7,9,10)$, whereas more recent ones have focused on the participation of the severity category (pack-years) of current smokers affecting snoring and $\mathrm{AHI}(17-19,21)$. Only one study considered the effects on $\mathrm{SaO}_{2}$ concentrations (19). Thus, the present study intended to clarify the repercussions of smoking severity, by current and former smokers, on objective sleep parameters.

Although subjective measurements have suggested that current smokers complain more about difficulty in initiating and maintaining sleep than non-smokers $(6,7)$ and Zhang et al. (20) observed that current smokers exhibited higher sleep latency and lower sleep efficiency in comparison to non-smokers, the present investigation showed no statistical differences in sleep latency and sleep efficiency among current, former and non-smokers. Comparisons of sleep architecture parameters across all status groups showed that current smokers exhibited a higher percent of sleep stage 1 and a lower percent of slow-wave sleep compared to non-smokers, as was reported by Zhang et al. (20). However, the magnitude of these differences has little clinical relevance. The previous findings of subjective nocturnal awakenings (9), difficulty in maintaining sleep (6), difficulty in waking up (7), loss of 
sleep quality $(6,7)$, poor sleep $(7,8)$ and poor daytime performance (6) of smokers, are supported by other types of data of the present study, such as: association of smoking habits with sleep fragmentation and with sleepiness. We observed that current and former smokers exhibited higher arousal index compared with non-smokers. These indexes were also higher among current and former smokers with pack-years $\geq 15$ compared with the respective subgroup with pack-years $<15$. However, the linear regression, considering gender, $\mathrm{BMI}$, age, $\mathrm{AHI}$, smoking status and pack-year categories, showed that, besides gender and $\mathrm{AHI}$, only current smokers with pack-years $\geq 15$ influenced the arousal index value. This suggests that smoking severity plays a role in sleep fragmentation, especially among current smokers.

Former smokers presented Epworth sleepiness scores higher than the normal threshold (24), which were also higher compared to non-smokers or among former smokers with pack-years $\geq 15$ compared with those with $<15$. Although these findings were not observed among current smokers, the linear regression analysis, considering gender, BMI, age, AHI, smoking status and pack-year categories, showed that the Epworth score was influenced by $\mathrm{BMI}, \mathrm{AHI}$, current smokers with pack-years $\geq 15$, and former smokers with pack-years $\geq 15$. Once more smoking severity was associated with sleep data.

Reports of the effects of smoking habits on $\mathrm{AHI}$ are contradictory $(17-19,21,29)$. Moreno et al. (29) found an association between smoking and obstructive sleep apnea estimated by the Berlin questionnaire. Wetter et al. (21) reported that current smokers are more closely associated with snoring and moderate or severe levels of $\mathrm{AHI}$ than nonsmokers, and this association was aggravated by the number of pack-years. Former smokers after adjustment for confounding factors were not related to snoring (21). Kashyap et al. (17) demonstrated that the percent of non-smokers was greater among patients with $\mathrm{AHI}<5$ than those with $\mathrm{AHI}$ $\geq 10$, and that current smokers were 2.5 times more likely to have $\mathrm{AHI} \geq 10$ than former and non-smokers combined and that former smokers were not more likely to have $\mathrm{AHI} \geq 10$ in comparison to non-smokers. Hoffstein (18) and Casasola et al. (19) reported no significant association between smoking exposure and apnea severity. Although Casasola et al. (19) suggested the need of a larger sample to assess this possible association, the present study using data from 1492 subjects found no differences in mean $\mathrm{AHI}$ among current, former and non-smokers. Moreover, after adjusting for age, $\mathrm{BMI}$ and gender, current and former smokers and their packyear subcategories remained not associated with $\mathrm{AHI} \geq 5$ compared with non-smokers.

In the present investigation, although former smokers spent more sleep time at $\mathrm{SaO}_{2}<90 \%$ than non-smokers, the logistic regression analysis, controlling for BMI, gender, age and $\mathrm{AHI}$, showed that only current smokers with pack-years $\geq 15$ were 1.9 times more likely to spend over $5 \%$ of TST at $\mathrm{SaO}_{2}<90 \%$ compared with non-smokers. Additionally, current smokers with pack-years $\geq 15$ spent more sleep time at $\mathrm{SaO}_{2}<90 \%$ than those with pack-years $<15$. These results are consistent with the study conducted by Casasola et al. (19), who demonstrated that current smokers had lower oxygen saturation and higher carboxyhemoglobin levels during sleep than non-smokers. They also detected a correlation between number of pack-years and the nocturnal hypoxia index of current smokers.

Since smoking habits are not associated with $\mathrm{AHI} \geq 5$ but influence arousal index, Epworth score and oxyhemoglobin desaturation during sleep, especially for current smokers, it is possible that smoking habits play a role in upper airway resistance syndrome. Gothe et al. (30) reported that nicotine administration prior to sleep results in a decrease in upper airway resistance, perhaps by an increase in upper airway muscle tone during sleep. However, Kashyap et al. (17) suggested that the progressive decrease in blood nicotine concentrations, after a few hours of sleep, was related to an increase in upper airway resistance, possibly as a result of upper airway inflammatory processes caused by smoking $(3,13,19,31)$. It is possible that former smokers recover from this inflammatory process after a period of cessation of smoking, thus improving arousal index values. Likewise, such behavior should also improve the mechanisms involved in oxyhemoglobin saturation levels during sleep.

Unfortunately, we could not determine the recovery time for sleep respiratory parameters after smoking cessation. Further studies are important to investigate this topic, as well as the dose-response association of smoking and sleeprelated outcomes without the dichotomized pack-years variable. Because non-smokers composed $63.5 \%$ of the sample (more than half carrying zero values for pack-years), we dichotomized severity categories according to the median value of pack-years smoked by our group.

Despite the limitations of the present study, our data indicated that, in addition to the influence of smoking status, smoking severity (number of pack-years accumulated during the periods of smoking) plays an independent and important role in impaired sleep parameters, especially those related to sleep-disorder breathing, such as Epworth score, arousal index and oxyhemoglobin desaturation during sleep. These findings were more pronounced in current smokers, supporting the subjective complaints of smokers reported in other studies. Behavioral intervention for smoking cessation should be emphasized because 
the deleterious effects of smoking on sleep fragmentation and oxyhemoglobin desaturation were decreased in former smokers. Likewise, patients suffering from sleep apnea should be well-informed to avoid smoking in order to prevent greater impairment of sleep parameters.

\section{References}

1. Edwards R. The problem of tobacco smoking. BMJ 2004; 328: 217-219.

2. Higgins MW, Enright PL, Kronmal RA, Schenker MB, AntonCulver $\mathrm{H}$, Lyles M. Smoking and lung function in elderly men and women. The Cardiovascular Health Study. JAMA 1993; 269: 2741-2748.

3. Willemse BW, Postma DS, Timens W, ten Hacken NH. The impact of smoking cessation on respiratory symptoms, lung function, airway hyperresponsiveness and inflammation. Eur Respir J 2004; 23: 464-476.

4. Willemse BW, ten Hacken NH, Rutgers B, Postma DS, Timens W. Association of current smoking with airway inflammation in chronic obstructive pulmonary disease and asymptomatic smokers. Respir Res 2005; 6: 38.

5. Patten CA, Choi WS, Gillin JC, Pierce JP. Depressive symptoms and cigarette smoking predict development and persistence of sleep problems in US adolescents. Pediatrics 2000; 106: E23.

6. Phillips BA, Danner FJ. Cigarette smoking and sleep disturbance. Arch Intern Med 1995; 155: 734-737.

7. Wetter DW, Young TB. The relation between cigarette smoking and sleep disturbance. Prev Med 1994; 23: 328-334.

8. Soldatos CR, Kales JD, Scharf MB, Bixler EO, Kales A. Cigarette smoking associated with sleep difficulty. Science 1980; 207: 551-553.

9. Delasnerie-Laupretre N, Patois E, Valatx JL, Kauffmann F, Alperovitch A. Sleep, snoring and smoking in high school students. J Sleep Res 1993; 2: 138-142.

10. Lindberg E, Taube A, Janson C, Gislason T, Svardsudd K, Boman G. A 10-year follow-up of snoring in men. Chest 1998; 114: 1048-1055.

11. Kauffmann F, Annesi I, Neukirch F, Oryszczyn MP, Alperovitch $A$. The relation between snoring and smoking, body mass index, age, alcohol consumption and respiratory symptoms. Eur Respir J 1989; 2: 599-603.

12. Khoo SM, Tan WC, Ng TP, Ho CH. Risk factors associated with habitual snoring and sleep-disordered breathing in a multi-ethnic Asian population: a population-based study. Respir Med 2004; 98: 557-566.

13. Bloom JW, Kaltenborn WT, Quan SF. Risk factors in a general population for snoring. Importance of cigarette smoking and obesity. Chest 1988; 93: 678-683.

14. Franklin KA, Gislason T, Omenaas E, Jogi R, Jensen EJ, Lindberg $\mathrm{E}$, et al. The influence of active and passive smoking on habitual snoring. Am J Respir Crit Care Med 2004; 170: 799-803.

15. Corbo GM, Fuciarelli F, Foresi A, De Benedetto F. Snoring in children: association with respiratory symptoms and passive smoking. BMJ 1989; 299: 1491-1494.

16. Forastiere F, Corbo GM, Michelozzi P, Pistelli R, Agabiti N, Brancato $G$, et al. Effects of environment and passive smoking on the respiratory health of children. Int $J$ Epidemiol 1992; 21: 66-73.
17. Kashyap R, Hock LM, Bowman TJ. Higher prevalence of smoking in patients diagnosed as having obstructive sleep apnea. Sleep Breath 2001; 5: 167-172.

18. Hoffstein V. Relationship between smoking and sleep apnea in clinic population. Sleep 2002; 25: 519-524. [author indexed as Hoflstein V].

19. Casasola GG, Alvarez-Sala JL, Marques JA, SanchezAlarcos JM, Tashkin DP, Espinos D. Cigarette smoking behavior and respiratory alterations during sleep in a healthy population. Sleep Breath 2002; 6: 19-24.

20. Zhang L, Samet J, Caffo B, Punjabi NM. Cigarette smoking and nocturnal sleep architecture. Am J Epidemiol 2006; 164: 529-537.

21. Wetter DW, Young TB, Bidwell TR, Badr MS, Palta M. Smoking as a risk factor for sleep-disordered breathing. Arch Intern Med 1994; 154: 2219-2224.

22. Ministério da Saúde INCA (Instituto Nacional de Câncer) e Coordenação de Prevenção e Vigilância. Prevalência de Tabagismo no Brasil. Dados dos inquéritos epidemiológicos em capitais brasileiras. Rio de Janeiro: Ministério da Saúde; 2004.

23. Centers for Disease Control and Prevention (CDC). Cigarette smoking among adults - United States, 1992, and changes in the definition of current cigarette smoking. MMWR Morb Mortal Wkly Rep 1994; 43: 342-346.

24. Johns MW. A new method for measuring daytime sleepiness: the Epworth sleepiness scale. Sleep 1991; 14: 540-545.

25. Rechtschaffen A, Kales A. A manual of standardized terminology, techniques, and scoring systems for sleep stages of human subjects. Los Angeles: UCLA Brain Information Service/Brain Research Institute; 1968.

26. American Sleep Disorders Association. EEG arousals: scoring rules and examples: a preliminary report from the Sleep Disorders Atlas Task Force. Sleep 1992; 15: 173-184.

27. American Academy of Sleep Medicine Task Force. Sleeprelated breathing disorders in adults: recommendations for syndrome definition and measurement techniques in clinical research. Sleep 1999; 22: 151-153.

28. Anonymous. SPSS 13.0 brief guide. Chicago: SPSS Inc.; 2004.

29. Moreno CR, Carvalho FA, Lorenzi C, Matuzaki LS, Prezotti $S$, Bighetti $P$, et al. High risk for obstructive sleep apnea in truck drivers estimated by the Berlin questionnaire: prevalence and associated factors. Chronobiol Int 2004; 21: 871879.

30. Gothe B, Strohl KP, Levin S, Cherniack NS. Nicotine: a different approach to treatment of obstructive sleep apnea. Chest 1985; 87: 11-17.

31. van der Vaart H, Postma DS, Timens W, Hylkema MN, Willemse BW, Boezen HM, et al. Acute effects of cigarette smoking on inflammation in healthy intermittent smokers. Respir Res 2005; 6: 22. 